\title{
Cowpea Aphid Resistance In Cowpea Line CB77 Functions Primarily Through Antibiosis And Eliminates Phytotoxic Symptoms of Aphid Feeding
}

Jacob R. MacWilliams

UC Riverside: University of California Riverside

Quentin Chesnais

University of California Riverside

Paul Nabity

University of California Riverside

Kerry Mauck

University of California Riverside

Isgouhi Kaloshian ( $\square$ isgouhi.kaloshian@ucr.edu )

University of California Riverside https://orcid.org/0000-0002-9873-2810

\section{Research Article}

Keywords: Plant resistance, Electrical penetration graph, Phytotoxic, Insect performance, Antibiosis, Antixenosis

Posted Date: June 14th, 2021

DOI: https://doi.org/10.21203/rs.3.rs-522914/v1

License: (c) (i) This work is licensed under a Creative Commons Attribution 4.0 International License.

Read Full License 


\section{Abstract}

Cowpea (Vigna unguiculata) is one of the most important crops in semiarid areas of the world, where it thrives in hot, dry conditions. While cowpea is able to withstand abiotic stresses, it suffers serious losses from biotic antagonists, including infestation by the cowpea aphid (Aphis craccivora). Cowpea aphid infestations are highly destructive, especially on young plants. However, it is unclear whether cowpea aphid damage is the result of aphids having phytotoxic effects on their hosts, or simple density effects. To better understand cowpea aphid damage and the potential for resistance traits to mitigate aphid impacts, we evaluated phenotypic changes in cowpea in response to variable aphid densities and systemic versus local infestations. Low aphid densities induced leaf distortions and pseudogalling, suggesting that cowpea aphids are phytotoxic to cowpea. Resistance to the cowpea aphid has been previously identified in an African cowpea germplasm, and near isogenic lines (NILs) containing resistance quantitative trait loci (QTL) were generated in the California blackeye cultivar background. Using a series of performance assays, we determined that resistance conferred by the two QTL counteracts aphid phytotoxicity and severely limits aphid growth and fecundity. Using choice assays, a preference by cowpea aphids for the susceptible NIL was observed. Electrical penetration graph analysis revealed that the resistance phenotype includes weak surface level deterrence and strong phloem based resistance that manifests during the sap ingestion phase. Our study provides evidence of phytotoxic traits in A. craccivora while identifying a viable means of counteracting aphid damage and reproductive potential through resistance.

\section{Key Message}

- Cowpea aphids are phytotoxic causing damage even at low aphid densities.

- Endogenous resistance to cowpea aphids is needed to better combat cowpea aphid infestation.

- Antibiosis was determined to be the main resistance mechanism in cowpea line CB77 and acts in the phloem.

- Antixenosis was determined to be the secondary resistance mechanism acting at the surface.

\section{Introduction}

Cowpea (Vigna unguiculata) is a multi-functional crop that serves as a source of food and fodder, and as a cover crop, in semi-arid regions of the world (Singh et al. 2002; Langyintuo et al. 2003; Timko and Singh 2008). Cowpea is able to fill these many needs in arid locations because it is able to withstand harsh growing conditions such as heat and drought stress (Hall et al. 2002; Hall 2004) as well as low soil fertility and variable soil pH (Elawad and Hall 1987; Fery 1990). However, while cowpea is robust to many adverse abiotic conditions, it is vulnerable to several biotic stressors that curtail growth and yield potential.

The cowpea aphid (Aphis craccivora) is one of the most important biotic antagonists of cowpea. Aphids feed by navigating long, flexible stylets between mesophyll cells to reach phloem sieve tube elements, 
where they subsequently engage in salivation and prolonged periods of passive sap ingestion (Tjallingii and Esch 1993; Tjallingii 2006). This process typically inflicts minimal cellular damage and does not involve tissue removal. However, aphid feeding can still facilitate negative outcomes for the host in several ways. Because aphids typically leave cells intact during feeding, and viruses require live cells to establish infections, aphid feeding is optimized for virus transmission. Cowpea aphids act as viral vectors for over 50 plant viruses including the notorious cowpea-aphid-borne mosaic virus (genus Potyvirus, family Potyviridae) (Chan et al. 1991; Singh 2014). Aphid feeding also results in leaves accumulating honeydew - the sugar-water fecal material excreted at high rates by aphids ingesting phloem sap. Honeydew acts as a carbon source for opportunistic molds, which subsequently block light from reaching leaf surfaces (Reynolds 1999). In cowpea, aphid populations can rapidly increase, resulting in an abundance of honeydew on the largest, most photosynthetically active leaves. Finally, aphids can inflict direct damage to plants by removing nutrients and continuously secreting salivary effectors that modify plant growth and development (Kaloshian and Walling 2016).

Effector-based mechanisms are hypothesized to underlie the severe damage that cowpea aphid inflicts on its host; feeding by cowpea aphids induce dramatic symptoms, including chlorosis, stunted growth and pseudogalling - a type of leaf rolling reminiscent of the gall structures induced by certain arthropods and fungi (Jackai and Daoust 1986; Goggin et al. 2017; Omoigui et al. 2017). Although not formally characterized as such, the damage phenotype induced by cowpea aphid resembles that induced by "phytotoxic" aphid species. An aphid is considered to be phytotoxic if it causes chlorosis or leaf deformity in host plants even at low populations. Two of the most economically important phytotoxic aphids are the Russian wheat aphid (Diuraphis noxia) and greenbug (Schizaphis graminum) (Miles 1999; Nicholson et al. 2012; Nicholson and Puterka 2014). Both species induce chlorosis and pseudogalling at low densities, ultimately reducing grain yield (Burd and Burton 1992; Burd et al. 1993). In contrast, nonphytotoxic species, such as the pea aphid (Acyrthosiphon pisum) and the green peach aphid (Myzus persicae) cause little to no observable damage at low populations.

In the present study, we performed controlled population feeding experiments to determine if cowpea aphids are phytotoxic to their hosts at low populations. These experiments were carried out with both cowpea aphid-susceptible and resistant genetic material undergoing phenotypic evaluation for breeding potential. Resistance against cowpea aphid is a crucial management tactic given that cowpea is cultivated widely in areas of the world where insecticide use is cost prohibitive (Singh and Allen 1980; Obopile 2006; Souleymane et al. 2013). Without the use of pesticides, prolonged cowpea aphid infestations can cause over $50 \%$ losses in crop yield (Obopile 2006). This highlights the need for identifying endogenous cowpea resistance to cowpea aphids to better protect cowpea from aphid infestations. In 2013, a source of resistance was identified in an African breeding line (IT97K-556-6) (Souleymane et al. 2013). Using recombinant inbred lines (RILs), derived from a susceptible California blackeye cultivar (CB27) and the resistant African breeding line (IT97K-556-6), the sources of the resistance were mapped to two quantitative trait loci (QTLs). The resistance QTLs were found to be a major QTL, QAC-vu7.1, and a minor QTL, QAC-vu1.1 (Huynh et al. 2015). The mechanism of the resistance mediated by these two QTLs remains unknown. 
Here, as a component of experiments to understand potential phytotoxic traits in cowpea aphid, we performed behavioral and electrophysiological experiments to characterize the resistance phenotype associated with these two QTLs. Plant resistance to insects has been classified into three different subcategories: antibiosis, antixenosis, and tolerance (Smith 1989). Antibiosis-based resistance affects the insect biology and growth, while antixenosis-based resistance affects the insect behavior. Tolerance on the other hand is the ability of the plant to withstand insect damage. Based on previous work with the resistant germplasm, we hypothesized that the type of resistance associated with QTL QAC-vU7.1 and QAC-vu1.1 may include both antixenotic and antibiotic effects (Souleymane et al. 2013; Huynh et al. 2015). To test this hypothesis while fully characterizing the cowpea damage phenotype, we obtained a pair of near isogenic lines (NILs) with and without resistance traits. Using these lines, we quantified phytotoxic responses to controlled aphid feeding at local and systemic sites, no-choice and choice behavioral assays, and fine-scale analysis of aphid stylet activities in the plant using the electrical penetration graphing (EPG) technique, which allows researchers to determine the precise location in which resistance interferes with host use by aphids (Tjallingii 2006).

\section{Materials And Methods}

\section{Plant and aphid growth conditions}

Two lines of cowpea (Vigna unguiculata) ), susceptible California blackeye (CB46) and its resistant NIL (CB77), were grown in UC Mix 3 soil (agops.ucr.edu/soil/) in 24 oz plastifoam cups and fertilized weekly with MiracleGro (18 - $18-21$; Stern's MiracleGro Products). Plants were grown in a pesticide free plant growth room at $28 \pm 2^{\circ} \mathrm{C}$ and $16: 8$ light:dark photoperiod.

The cowpea aphids were collected from a field in Riverside, California, in the summer of 2016. Since then, the aphids were reared on the susceptible cowpea line CB46 in a pesticide free greenhouse or a plant growth chamber and maintained at $28 \pm 2^{\circ} \mathrm{C}$ with a $16: 8$ light:dark photoperiod. Aphis gossypii (cotton melon aphid) was used as a conspecific non-specialist in damage experiments. The colony was established from aphids collected from squash about a decade ago near Reedley, CA, USA. Melons (Cucumis melo cv. "Iroquois") served as the host in all experiments and were used to maintain the aphid colony under the same conditions as for $A$. craccivora.

\section{Aphid damage assay}

One-week-old susceptible cowpea plants were infested with 15 mixed stages of 3rd and 4th instars, and adults of cowpea aphids or cotton melon aphids for 15 days. Plants were encased in plastic pollination bags with minute holes (Seedburo, SKU: S27) to restrict aphids to the plant and were maintained at $26 \pm$ $2^{\circ} \mathrm{C}$ with a 16:8 light:dark photoperiod for 15 days. Plants were exposed to two different aphid densities, with one density of aphids maintained at a constant 15 aphids on the entire plant (constant cowpea aphid density), and a second density where aphids were allowed to grow and reproduce without any numeric restriction (variable cowpea aphid density). To keep the cowpea aphids at a constant density, newborn nymphs were removed daily, and the population was maintained at 15 aphids. Newborn nymphs 
were kept when the number of the original aphids dropped below 15. The cotton melon aphids were allowed to grow without any numeric restriction like the variable cowpea aphid density (variable cotton melon aphid density). The presence or absence of damage symptoms induced by the aphids were monitored daily throughout the experiment (chlorosis, pseudogalling, and/or stunted growth). For each aphid density or species, 8-10 plants were used per experiment and the experiment was performed three times.

\section{Local vs systemic damage assay}

A single unifoliate leaf of one-week-old susceptible cowpea plants was infested with 15 mixed stages of 3rd and 4th instars and adults of cowpea aphids using a mesh sleeve bag. Plants were maintained at $22-28^{\circ} \mathrm{C}$ with a $16: 8$ light:dark photoperiod for 15 days. On the uninfested areas of the plants, damage symptoms including chlorosis, pseudogalling, and/or stunted growth were monitored daily throughout the 15-day period. After 15 days, the mesh sleeves were removed and the symptoms on the infested leaves as well as on the entire plants were documented. Three plants were infested per experiment and the experiment was performed three times.

\section{Aphid no-choice assay}

Two-week-old susceptible and resistant cowpea plants were infested with 20 adult apterous aphids on a single unifoliate leaf and enclosed in a mesh sleeve bag. The plants were left undisturbed for six days after which the total number of aphids was counted on the leaf. A total of 15 plants were used for each cowpea line.

\section{Aphid fecundity assay}

Age synchronized cohorts of one-day-old adult aphids were developed by clip-caging adult apterous aphids to the adaxial side of a susceptible cowpea plant for $24 \mathrm{~h}$ to lay progeny. After this period, the adult aphids were removed with a fine tip paint brush and the first instars they produced were allowed to develop to maturity. A single, age synchronized, one-day-old adult cowpea aphid was transferred to a naive two-week-old unifoliate leaf of either a susceptible or a resistant cowpea plant and clip-caged on the adaxial side. The cages were monitored daily, for one week, and the survival of the adult aphid and the number of nymphs produced were recorded. After counting, the newly produced laid nymphs were removed. A single leaf per plant was infested and a total of 16 plants of each cowpea line were used.

\section{Aphid growth rate assay}

Ten cowpea aphid adults were clip-caged onto the adaxial side of a susceptible or resistant cowpea leaf. After $24 \mathrm{~h}$, the adult aphids were removed, and ten newborn nymphs were left on the leaf in the clip cage. After six days, the surviving aphids were counted and weighed with a microbalance (CN HG 01.121, Sartorius). 
The mean relative growth rate (MRGR) was calculated as the difference of logarithms of the mean weight of day-old aphid nymphs and the mean weight of the surviving aphid nymphs divided by the number of days $\left(M R G R=\left(\log W_{\text {surviving }}-\log W_{\text {day-old }}\right) /\right.$ Number of days $)$. Twelve cages were used per cowpea line.

\section{Electrical penetration graph}

A DC-electrical penetration graph (DC-EPG system) was used for the EPG analysis (Tjallingii 1988). The EPG technique has been developed to monitor the probing activities of arthropods with piercing mouthparts when probing inside plants. The EPG waveforms are determined depending on the stylet tip positions in leaf tissue and the insect's behavior (Tjallingii 1988). An EPG is performed by securing an electrode onto an aphid and placing a second electrode in the soil next to plant roots. Cowpea aphids were tethered to a $12.5 \mu \mathrm{m}$ gold wire on their dorsal side of the abdomen using a water-based, conductive silver glue (Cervantes and Backus 2018). After an hour-long starvation period, tethered aphids were placed on the abaxial side of a two-week-old unifoliate leaf and a second electrode was placed in the soil of the potted plant. Simultaneous recordings for eight aphids were performed on a Giga-8 DC-EPG amplifier for $8 \mathrm{~h}$. The aphid-plant systems were housed in a Faraday cage in a climate-controlled room at $24 \pm 1^{\circ} \mathrm{C}$. Each recording session had half of the aphids on susceptible plants and half on resistant plants. At the end, a total of 25 susceptible and 30 resistant EPGs were obtained and analyzed. The analysis of the EPG variables and waveforms were performed with PROBE 3.5 software (EPG systems, www.epgsystems.eu) naming convention based (Ebert et al. 2015). These EPG parameters were based on six different waveforms corresponding to stylet pathways in plant tissues other than phloem and xylem (C), to potential drops (i.e., intracellular stylet punctures) (pd), to salivation in phloem elements (E1), to passive phloem sap ingestion (E2), to active xylem sap ingestion (G), and to derailed stylet mechanics (F). The calculations were performed with EPG-Calc 6.1 software (Giordanengo 2014).

\section{Aphid choice assay}

A large, modified petri dish arena was placed above two 2-week-old cowpea plants, one of each resistant and susceptible line, to evaluate aphid preference. The arena had two holes of $2 \mathrm{~cm}$ diameter cut out of the bottom of the plate, directly across from each other. When positioned over paired leaves from each treatment, the aphids were able to choose between equal tissue amounts of each leaf, spaced equidistant within the plate. Aphids were introduced to the arena through a third $2 \mathrm{~cm}$ hole directly in the center area between the two choice options. This hole was fitted on the underside (exterior) of the arena with a screw cap to which a modified (shortened) $50 \mathrm{~mL}$ conical tube containing the aphids could be affixed (Online Resource 1). A group of twenty aphids (starved for $1 \mathrm{~h}$ prior to use) was introduced to the arena through this release mechanism. The number of aphids feeding on each leaf was recorded at 2, 3, 6, and $24 \mathrm{~h}$ after release. Four to five plant pairs were used per experiment and the experiment was performed four times.

\section{Aphid dispersal assay}


The rate of cowpea aphid dispersal in response to resistant cowpea was used to monitor aphid deterrence. Aphid dispersal was measured using a behavior dispersal assay similar to that described in Mauck et al. (2010). Bioassay arenas were constructed from $100 \times 15 \mathrm{~mm}$ petri dishes, with two conjoining holes $\left(17 \mathrm{~mm}^{2}\right)$ cut in the center. A unifoliate leaf from one of the two cowpea plant types being compared was exposed on one side of the conjoining holes, and the other choice option was immediately adjacent occupying the second conjoined hole (Online Resource 2). After a 15-min chill at $4^{\circ} \mathrm{C}$, twenty 4 th stage instars and adult aphids were placed on a piece of filter paper. The filter paper with the chilled aphids was then placed directly on one of the exposed leaves. The placement of the filter paper on the leaf ensured that the aphids contacted the initial leaf they were placed on before dispersal. The filter paper was removed after an $\mathrm{h}$ when all aphids had dispersed and the location of the aphids were documented at 1, 2, 6, and $24 \mathrm{~h}$. The cowpea plants screened against each other included, susceptible with resistant, susceptible with susceptible and resistant with resistant. Five plant pairs were used per experiment and the experiment was performed twice.

\section{Statistical analyses}

We used one-way analysis of variance (ANOVA) followed by Tukey HSD tests to assess aphid population damage assay using GraphPad Prism version 8 (GraphPad Software, San Diego, California USA). The aphid no-choice experiment was analyzed using a two-tailed $t$-test using GraphPad Prism version 8 (GraphPad Software, San Diego, California USA). We used generalized linear models (GLM) with a likelihood ratio and chi-square test to analyze adult aphid fecundity and survival rate using $\mathrm{R}$ software (version 3.6.0) (R Core Team, 2019). Two-tailed $t$-test using GraphPad Prism version 8 (GraphPad Software, San Diego, California USA) was used to analyze the nymph survival and MRGR. Aphid feeding behavior was analyzed using generalized linear models (GLM) with a likelihood ratio and Chi-square test $\left(x^{2}\right)$. We had three types of data: (a) event duration, (b) frequency of penetration events and (c) time delay until the first occurrence of an event. Event durations were modeled using GLM with a gamma (link = "inverse") distribution and frequency of penetration were modeled using GLM with poisson (link = "identity") distribution. Time delay data were modeled using the Cox proportional hazards (CPH) model and we treated cases where the given event did not occur as censored. The assumption of validity of proportional hazards was checked using the functions "coxph" and "cox.zph", respectively (package R:

"survival"). The fit of all generalized linear models was controlled by inspecting residuals and QQ plots. Aphid choice assays were analyzed using Friedman tests for the overall model and Kruskal-Wallis tests for each individual time point (Minitab v. 14). Aphid dispersal assays were analyzed using GLMs for the overall repeated measures model, followed by univariate tests to explore treatment effects within each time point (Minitab v. 14).

\section{Results}

\section{Damage caused by cowpea aphids at point of feeding and distal sites}


Two different cowpea aphid population densities (constant and variable/increasing) were screened to observe the effect of damage and determine if symptoms consistent with phytotoxicity occur even at low population densities. A third treatment, feeding by the generalist, cotton melon aphid was included because it is phylogenetically closely related to the cowpea aphid but is not adapted to cowpea and causes no damage to the plant (Song et al. 2016). In the variable cowpea aphid density, all three measured symptoms, chlorosis, pseudogalling, and stunted growth, were observed (Fig. 1). These damage symptoms first became apparent at the end of week 1 and increased in severity by the end of week 2. Damage symptoms were also seen in the constant cowpea aphid density, with the majority of the damage symptoms observed as pseudogalling (Fig. 1B). Unlike the variable cowpea aphid density, where every plant exhibited at least one of the expected symptoms, only half of the constant cowpea aphid density plants exhibited a symptom(s) (Fig. 1D). Damage symptoms on the constant cowpea aphid density plants were localized to areas where aphids clustered (Online Resource 3 ). In a follow up experiment quantifying local $v s$. systemic damage explicitly, no damage was observed in the uninfested plant tissues. The only observed damage was on the infested unifoliate leaf (Online Resource 4).

As expected, no damage was observed on plants with the variable cotton melon aphid density (Fig. 1). After the 15-day infestation period, the total number of aphids was calculated for the variable aphid densities. The cotton melon aphid density was found to be on average less than 15 aphids, equivalent to the number of aphids used for the constant cowpea aphid density (Online Resource 5), while the variable cowpea aphid density had more than 15 -fold higher aphids than either of the other two aphid populations.

\section{Aphid performance metrics under no-choice conditions}

Initial no-choice assays indicated a stark difference in aphid population growth on resistant $v s$. susceptible cowpea lines (Fig. 2). The cowpea aphids feeding on susceptible plants had about 5 -fold higher numbers than those on the resistant plants. To determine if these effects may be due to an antibiosis resistance mechanism acting on adult aphids, single age-synchronized one-day-old adult aphids were clip-caged onto leaves and fecundity and survival were monitored for a week. Adults feeding on the resistant cowpea had significantly lower fecundity than aphids feeding on the susceptible line (Fig. $3 \mathrm{~A}, \mathrm{GLM}$, Chisq $=41.704, P<0.001)$. Adult aphid survival was also significantly lower on the resistant line compared to the susceptible (Fig. 3B, GLM, Chisq $=8.049, P=0.005$ ).

To investigate whether cowpea resistance affected aphid growth rates, ten newborn aphid nymphs were caged onto susceptible or resistant NILs. After six days, significantly more nymphs survived on the susceptible plants compared to the resistant plants (Fig. 4A). The nymphs feeding on the susceptible plants also had significantly higher MRGR than the nymphs feeding on the resistant plants (Fig. 4B). Together, these no-choice performance metrics suggest that the resistance in cowpea line CB77 involves antibiosis and has negative effects on the aphid's ability to reproduce, survive, and grow.

\section{Electrical penetration graph}


A representative EPG diagram of cowpea aphids feeding on both susceptible and resistant cowpea is shown in Online Resource 6. The differences in aphid feeding behavior on the two different cowpea lines starts at the beginning of the probing process. The time to first probe (first entry into the plant) is significantly faster for the aphids placed on the susceptible line compared to the resistant line (Table 1). The aphids feeding on the susceptible cowpea line had a significantly longer probing time than the aphids feeding on the resistant cowpea line; aphid stylets were inserted in susceptible plant tissues for 30 more min than in resistant tissues (Fig. 5, Table 1). The aphids feeding on the susceptible cowpea line spent one $h$ less in the pathway (C) phase than aphids feeding on the resistant cowpea line. This difference indicates that aphids on the resistant cowpea are spending more time trying to reach the phloem than those on the susceptible cowpea line (Fig. 5, Table 1). The difference in the number of $C$ phases is in line with the differences seen in the number of potential drops (pd). There was a higher number of $\mathrm{C}$ phases and more potential drops $(\mathrm{pd})$ for aphids feeding on the resistant cowpea than the aphids feeding on the susceptible cowpea.

Aphids also differed in feeding parameters describing interactions with phloem sieve elements (the $E$ phases). The potential $E$ index is calculated as the percentage of time spent in the $E$ phases after the subtraction of the time needed to first reach $E$ and is a measure of how consistently insects feed following the first phloem contact, with higher numbers indicating more consistent feeding (Van Helden and Tjallingii 1993). The potential E index was significantly higher for aphids feeding on the susceptible cowpea line relative to aphids feeding on the resistant cowpea line (Table 1). Aphids feeding on the susceptible cowpea also salivated (E1) more frequently than on the resistant line but not for longer periods of time (Fig. 5, Table 1). One of the most notable differences observed in the phloem sieve element (E) phases was the inability of over half the aphids feeding on the resistant cowpea line to reach the phloem sap ingestion phase (E2) while $96 \%$ of aphids feeding on the susceptible cowpea line were able to do so (Table 1). When comparing only the aphids that successfully reached $\mathrm{E} 2$, individuals on the susceptible line were able to do so over an $\mathrm{h}$ faster compared to the resistant and ingested over an $\mathrm{h}$ longer (Fig. 5, Table 1).

Table 1 Cowpea aphid probing and feeding parameters on the susceptible (S) and resistant (R) cowpea NILS. 


\begin{tabular}{|c|c|c|c|c|}
\hline & & $S(n=25)$ & $R(n=30)$ & Stats \\
\hline \multirow[t]{4}{*}{ Probing phase } & Time to first $^{1}(h)$ & $\begin{array}{l}0.02 \pm \\
0.01\end{array}$ & $\begin{array}{l}0.06 \pm \\
0.02\end{array}$ & $\begin{array}{l}\text { Chi-sq = 7.119; } P= \\
0.008 \text { ** }\end{array}$ \\
\hline & \# Brief probes $(<3 \mathrm{~min})^{2}$ & $\begin{array}{l}9.72 \\
\pm 2.51\end{array}$ & $\begin{array}{l}8.267 \pm \\
1.05\end{array}$ & $\begin{array}{l}\text { Chi-sq }=3.214 ; P= \\
0.073 \mathrm{NS}\end{array}$ \\
\hline & \# & $\begin{array}{l}22.04 \pm \\
3.42\end{array}$ & $\begin{array}{l}27.73 \pm \\
2.24\end{array}$ & $\begin{array}{l}\text { Chi-sq = } 17.738 ; P \\
<0.001 * \star \star\end{array}$ \\
\hline & Duration $^{3}(\mathrm{~h})$ & $\begin{array}{l}7.07 \pm 0 \\
.19\end{array}$ & $\begin{array}{l}6.48 \pm \\
0.19\end{array}$ & $\begin{array}{l}\text { Chi-sq }=4.649 ; P \\
=0.031 *\end{array}$ \\
\hline \multirow[t]{3}{*}{$\begin{array}{l}\text { Pathway phase } \\
\text { (C) }\end{array}$} & $\#$ & $\begin{array}{l}25.04 \pm \\
3.46\end{array}$ & $\begin{array}{l}30.63 \pm 2 \\
.21\end{array}$ & $\begin{array}{l}\text { Chi-sq }=15.305 ; P \\
<0.001 * \star *\end{array}$ \\
\hline & $\begin{array}{l}\text { Minimum time }(C) \text { to first } E \text { in } \\
\text { probe containing } E(h)\end{array}$ & $\begin{array}{l}0.40 \pm \\
0.05\end{array}$ & $\begin{array}{l}0.37 \pm \\
0.05\end{array}$ & $\begin{array}{l}\text { Chi-sq }=0.367 ; P= \\
0.544 \text { NS }\end{array}$ \\
\hline & Duration (h) & $\begin{array}{l}3.32 \pm \\
0.31\end{array}$ & $\begin{array}{l}4.54 \pm 0 \\
.25\end{array}$ & $\begin{array}{l}\text { Chi-sq }=8.853 ; P \\
=0.003 * *\end{array}$ \\
\hline $\begin{array}{l}\text { Potential drops } \\
\text { (Pd) }\end{array}$ & \# & $\begin{array}{l}163.12 \pm \\
19.28\end{array}$ & $\begin{array}{l}203.10 \pm \\
14.89\end{array}$ & $\begin{array}{l}\text { Chi-sq }=118.88 ; P \\
<0.001 * \star \star\end{array}$ \\
\hline \multirow[t]{4}{*}{$\begin{array}{l}\text { Sieve element } \\
\text { salivation (E1) }\end{array}$} & \# & $\begin{array}{l}5.64 \pm \\
0.79\end{array}$ & $\begin{array}{l}3.85 \pm \\
0.42\end{array}$ & $\begin{array}{l}\text { Chi-sq }=14.388 ; P \\
<0.001 * \star\end{array}$ \\
\hline & Time to first $E$ from first probe $(h)$ & $\begin{array}{l}1.99 \\
\pm 0.40\end{array}$ & $\begin{array}{l}2.86 \pm \\
0.64\end{array}$ & $\begin{array}{l}\text { Chi-sq }=2.797 ; P= \\
0.094 \text { NS }\end{array}$ \\
\hline & Duration (h) & $\begin{array}{l}0.62 \pm \\
0.12\end{array}$ & $\begin{array}{l}0.92 \pm \\
0.17\end{array}$ & $\begin{array}{l}\text { Chi-sq }=2.226 ; P= \\
0.136 \mathrm{NS}\end{array}$ \\
\hline & $n^{4}$ & $\begin{array}{l}100 \% \\
(25 / 25)\end{array}$ & $\begin{array}{l}90 \% \\
(27 / 30)\end{array}$ & $P=0.242 \mathrm{NS}$ \\
\hline \multirow[t]{6}{*}{$\begin{array}{l}\text { Phloem sap } \\
\text { ingestion (E2) }\end{array}$} & \# & $\begin{array}{l}3.67 \pm \\
0.56\end{array}$ & $\begin{array}{l}2.5 \pm \\
0.44\end{array}$ & $\begin{array}{l}\text { Chi-sq }=34.286 ; P \\
<0.001 * \star *\end{array}$ \\
\hline & Time to first (h) & $\begin{array}{l}2.31 \pm \\
0.38\end{array}$ & $\begin{array}{l}3.94 \pm \\
0.67\end{array}$ & $\begin{array}{l}\text { Chi-sq = 22.619; } P \\
<0.001 * * *\end{array}$ \\
\hline & Time to first sustained $(\mathrm{h})$ & $\begin{array}{l}2.92 \pm \\
0.43\end{array}$ & $\begin{array}{l}4.24 \pm \\
0.69\end{array}$ & $\begin{array}{l}\text { Chi-sq }=21.632 ; P \\
<0.001 * \star *\end{array}$ \\
\hline & Potential $\mathrm{E}$ index $\left(\% \mathrm{E} \text { after } 1^{\mathrm{st}} \mathrm{E}\right)^{5}$ & $\begin{array}{l}57.33 \pm \\
6.41\end{array}$ & $\begin{array}{l}29.04 \pm \\
5.72\end{array}$ & $\begin{array}{l}U=163 ; P= \\
0.0014 \text { ** }\end{array}$ \\
\hline & Duration (h) & $\begin{array}{l}2.90 \pm \\
0.45\end{array}$ & $\begin{array}{l}1.43 \pm \\
0.39\end{array}$ & $\begin{array}{l}\text { Chi-sq }=4.089 ; P= \\
0.043 *\end{array}$ \\
\hline & $\mathrm{n}$ & $\begin{array}{l}96 \% \\
(24 / 25)\end{array}$ & $\begin{array}{l}46.7 \% \\
(14 / 30)\end{array}$ & $P<0.001 * \star \star$ \\
\hline Xylem (G) & $\#$ & $1 \pm 0$ & $1 \pm 0$ & $\begin{array}{l}\text { Not enough } \\
\text { repetition }\end{array}$ \\
\hline
\end{tabular}




\begin{tabular}{|c|c|c|c|c|}
\hline & Duration (h) & $\begin{array}{l}0.92 \pm \\
0.20\end{array}$ & $\begin{array}{l}0.96 \pm \\
0.22\end{array}$ & $\begin{array}{l}\text { Not enough } \\
\text { repetition }\end{array}$ \\
\hline & $n^{3}$ & $\begin{array}{l}12 \% \\
(3 / 25)\end{array}$ & $\begin{array}{l}10 \% \\
(3 / 30)\end{array}$ & \\
\hline $\begin{array}{l}\text { Stylet derailment } \\
\text { (F) }\end{array}$ & $\#$ & $2 \pm 0.52$ & $\begin{array}{l}1.75 \pm \\
0.41\end{array}$ & $\begin{array}{l}\text { Chi-sq }=0.005 ; P \\
=0.943\end{array}$ \\
\hline & Duration (h) & $\begin{array}{l}0.79 \pm \\
0.19\end{array}$ & $\begin{array}{l}1.08 \pm \\
0.21\end{array}$ & $\begin{array}{l}\text { Chi-sq = 0.293; } P= \\
0.589\end{array}$ \\
\hline & $\mathrm{n}$ & $\begin{array}{l}24 \% \\
(6 / 25)\end{array}$ & $\begin{array}{l}26.67 \% \\
(8 / 30)\end{array}$ & $P=1 \mathrm{NS}$ \\
\hline
\end{tabular}

Feeding and probing parameters measured from the aphids feeding on the two cowpea NILs, $n=$ number of individual aphids, and \# = number of phases measured. The statistics used are the following: ${ }^{1}$ Cox model, ${ }^{2}$ GLM (family=poisson), ${ }^{3}$ GLM (family=Gamma), ${ }^{4}$ Fisher's exact test, and ${ }^{5}$ Mann-Whitney U tests.

\section{Host selection behavior}

At the 2, 3 and $6 \mathrm{~h}$ time points for the two-way choice test, aphid participation was low (e.g., only a few aphids had emerged into the arena and/or made a choice), and aphids were equally present on resistant or susceptible leaves. However, at $24 \mathrm{~h}$, aphid participation was higher and most aphids had selected a feeding location, revealing a significant preference for the susceptible cowpea over the resistant (Fig. 6).

In a different type of assay, we monitored aphid dispersal after the aphids were directly released on either susceptible or resistant cowpea and another plant (susceptible or resistant) directly adjacent to it (Online Resource 2). Aphids released on both susceptible and resistant cowpea had low initial dispersal levels (Fig. 7A). However, after $2 \mathrm{~h}$ significant aphid dispersal was observed when the aphids were initially released on resistant cowpea screened with a susceptible cowpea (Res-Susc) (Fig. 7B). This dispersion level was not observed in the other plant combinations.

The difference in dispersion levels became even more significant after $24 \mathrm{~h}$ (Fig. 7D). Only about a third of the aphids that were initially released on resistant cowpea when screened with susceptible (Res-Susc) remained on the initial plant indicating a high level of aphid dispersal. In comparison, almost two thirds of the aphids were remaining on susceptible cowpea when initially released on susceptible cowpea screened with a resistant (Susc-Res). A similar level of dispersion was observed when the two cowpea lines were screened with each other (Susc-Susc, Res-Res) after $24 \mathrm{~h}$. Both screens observed a lower level of dispersion than the aphids released on resistant cowpea when screened with susceptible (Res-Susc). The aphids initially released on the resistant cowpea when screened with resistant (Res-Res) had a higher level of dispersal than aphids initially released on susceptible cowpea screened with a resistant (SuscRes). The high levels of dispersion when the aphids are initially released on resistant plants affirms the cowpea aphids' preference for susceptible cowpea and the involvement of antixenosis in the resistance. 


\section{Discussion}

Cowpea aphid infestation produces direct damage on susceptible cowpea plants that severely compromises yields. By controlling for infestation intensity, we were able to explore induction of phytotoxic symptoms and their relationship with aphid numbers. Our results revealed that even low levels of cowpea aphids can induce symptoms consistent with phytotoxicity on susceptible plants; half of the plants in controlled population treatments exhibited at least one symptom (chlorosis, pseudogalling, or stunting). With larger cowpea aphid numbers (variable population treatment) phytotoxic effects were more consistent, with all plants exhibiting at least one of the three symptom types, but no new, unique phytotoxic effects were apparent. The appearance of phytotoxic symptoms even at low cowpea aphid numbers indicates that this species should be considered as a phytotoxic aphid similar to the Russian wheat aphid and greenbug (Miles 1999; Nicholson et al. 2012; Nicholson and Puterka 2014). However, unlike these well-known examples, our experiments suggest that the cowpea aphid's induced symptoms are localized to the infestation sites and are not systemic (Deol et al. 2001). This pattern of phytotoxic effects is consistent with other reports of pseudogalling symptom induction by members of the Aphis genus when feeding on their main crop hosts. For example, the cotton melon aphid induces pseudogalling on cotton (Gossypium hirsutum) and melon (Miles 1990; Goggin et al. 2017). And the spirea aphid (Aphis spiraecola), can cause pseudogalling on apple (Maloideae) (Blackman and Eastop 1994; Goggin et al. 2017). In all cases, pseudogalling symptoms are induced on hosts that are highly suitable and easily exploited by each respective species. Our results, combined with those for other Aphis species, suggest that pseudogalling could be a general phytotoxic effect of feeding by members of the Aphis genus.

Understanding the suite of symptoms induced by cowpea aphids on susceptible germplasm, and their relation to aphid proliferation, facilitated characterization of the resistance mechanism in a NIL derived from germplasm that does not exhibit damage symptoms in response to cowpea aphid feeding (Souleymane et al. 2013). To produce the NIL used in our study, resistance in an African breeding line that lacked phytotoxic symptoms following cowpea aphid feeding was mapped to two QTLs and introgressed into an elite susceptible California blackeye cultivar (our susceptible line) (Huynh et al. 2015; Huynh et al. submitted). Our experiments confirm that the resistance is associated with the previously identified QTLs, as the resistant NIL did not express phytotoxic symptoms in response to cowpea aphid infestation in any of our experiments, whereas the susceptible line nearly always exhibited at least one of the three symptoms (chlorosis, pseudogalling, or stunting). Aphids also failed to thrive and reproduce on the resistant line; population growth was minimal and survival was about half of that seen for cowpea aphids on the susceptible line.

Through a combination of population growth and individual aphid performance assays, we found evidence that the mechanism of resistance in the NIL may operate, at least partially, through antibiosis. Aphid populations on the susceptible NIL were 5-fold higher than populations on the resistant cowpea after just six days (Fig. 2). Performance assays with individual aphids support antibiosis as a mechanism and suggest that resistant effects on aphids do not depend on there being multiple 
individuals and are likely present constitutively. Aphid survival was reduced on the resistant NIL and the mean relative growth rates of nymphs were also significantly lower (Figs. 3 and 4). Adult aphids also produced fewer progeny on the resistant line in both individual and population fecundity assays (Figs. 2 and 3). This difference in population growth between the two cowpea lines is similar to what is reported for the soybean aphid (Aphis glycines) growth on susceptible and resistant soybean (Glycine max) over a similar time period (Studham and Maclntosh 2013). This difference in aphid population growth can be attributed to soybean aphid mortality due to the antibiosis resistance gene Rag1 (Hill et al. 2004; 2006a; 2006b). In addition to aphid survival, aphid growth rate has been used as a parameter to identify antibiosis. Cowpea aphid resistance in Medicago truncatula was determined to have an antibiosis component by monitoring MRGR of cowpea aphid nymphs (Kamphuis et al. 2012). Similar to our study, the aphids feeding on the resistant $M$. truncatula also had a significantly lower MRGR than those on susceptible M. truncatula.

Our aphid performance experiments demonstrate that resistance present in the R-NIL has an antibiosis component that affects both survival and fecundity. To determine where in the feeding process this resistance operates, we employed the electrical penetration graphing (EPG) technique to quantify differences in stylet activities and acquisition of plant fluids (phloem sap, xylem contents) between the RNIL and S-NIL. This technique can also provide some insight into whether antixenosis is a component of the resistance mechanism. To parse these mechanisms, we analyzed specific parameters for each phase of the aphid-plant interaction. Surface-level resistance traits that operate through antixenosis will be evident if insects are delayed in initiating their first probe into plant tissue (Van Helden and Tjallingii 1993; Alvarez et al. 2006). Resistance traits in peripheral layers of plant tissue (epidermis/mesophyll) may be operating if insects carry out significantly more short test probes on resistant lines, perform a larger number of intracellular punctures, or if they take significantly longer to traverse the mesophyll to initiate phloem contact (Gabrys et al. 1997; Schwarzkopf et al. 2013). Stylet derailment (F) is another EPG parameter that can be used to identify resistance in the mesophyll (Tjallingii 1987). For example, in aphid-resistant wild potato (Solanum stoloniferum), green peach aphids had an increased number and duration of stylet derailment (F) compared to susceptible potato (Solanum tuberosum) indicating the aphids were met with resistance in the mesophyll (Alvarez et al. 2006). Another EPG parameter that is important in identifying resistance is the xylem (G) phase. Aphids ingest xylem sap to maintain water balance on sub-par hosts (Spiller et al. 1990; Tjallingii 1990). Soybean aphids feeding on different lines resistant soybean all ingested xylem sap before reaching the phloem $(E)$ and it is hypothesized that the after the ingestion of xylem sap on these resistant plants the aphids were negatively affected (DiazMontano et al. 2007). Resistance at the phloem level is evident if the insects take longer to reach their first sustained bout of sap ingestion, spend a reduced percentage of the total recording time ingesting sap, and if fewer insects successfully engage in sap ingestion (Van Helden and Tjallingii 1993; Alvarez et al. 2006). Resistance may also alter salivation patterns at the site of the phloem. Bouts of salivation (E1) are typically followed by sap ingestion (E2) but on resistant or incompatible plants this transition is not successful and instead of ingestion it results in phloem occlusion (Medina-Ortega and Walker 2015). The legume specialist pea aphid was able to ingest on fava bean (Vicia faba) without causing forisome 
occlusion (Walker and Medina-Ortega 2012). However when two generalist aphids, the green peach aphid and potato aphid (Macrosiphum euphorbiae), fed on fava bean they had an incompatible interaction. For both aphid species, stylet penetration led to forisome occlusion and little sap ingestion (Medina-Ortega and Walker 2015).

Considering the parameters described above, our EPG recordings provide evidence of both antixenosis and antibiosis-based resistance in non-vascular tissues. Aphids took almost three times longer to initiate the first probe into plant tissue on the R-NIL, which is consistent with surface-level antixenosis traits, as has been observed for surface-level antixenosis resistance to the green peach aphid in multiple Solanum species (Alvarez et al. 2006). Once probing was initiated, aphids on the R-NIL performed more probes in a shorter total probing period, but did not perform significantly more brief probes less than three min. This indicates that aphids do not have difficulty traversing the epidermis and immediately adjacent mesophyll, as most probes proceeded deeper than the first few cell layers. Aphids also performed slightly more pathway events (traversing the mesophyll layer to reach the phloem) and took longer to complete the pathway phase, but did not differ in the minimum time needed to reach the phloem within pathway events that ultimately proceeded to phloem contact. During the pathway phase, aphid also performed significantly more intracellular punctures (potential drops) on R-NIL plants, during which they presumably sampled cell contents (Martin et al. 1997). Overall, these results suggest that some resistance traits are operating in the surface and non-vascular cell layers because aphids perform more non-nutritive activities on R-NIL plants (starting new probes, traversing cell layers, intracellular punctures). However, it is unlikely that these factors are the main drivers of the dramatic reductions in aphid performance observed in our other experiments because $90 \%$ of the aphids on the R-NIL plants reached the phloem and we did not observe any differences in stylet derailment during the pathway phase.

Resistance factors that directly explain the reduced survival and growth metrics are strongly evident at the level of the phloem, specifically for phloem sap ingestion phase. Only half of the aphids recorded feeding on the R-NIL successfully engaged in phloem sap ingestion. Of those that were successful, they took more than an $\mathrm{h}$ longer to initiate sap ingestion, engaged in fewer ingestion events, and spent about half as much time ingesting after the first successful phloem contact (Table 1). These results suggest that the most effective resistance traits are operating at the level of the phloem sieve elements. It is interesting to note that this resistance operates almost exclusively in the ingestion phase, with few effects on salivation. Often, phloem based resistances are associated with differences in salivation occurrences and durations (Kamphuis et al. 2012; Sun et al. 2018; Peng and Walker 2020). For example, green peach aphids feeding on a resistant line of pepper (Capsicum spp.) salivated more frequently, and for longer bouts, relative to those on susceptible pepper (Sun et al. 2018). Similarly, cotton melon aphids feeding on resistant melon salivated for 2.8 times longer than cotton melon aphids on susceptible melon (Peng and Walker 2020). In contrast to this, a significantly shorter salivation time was reported for cowpea aphids feeding on resistant $M$. truncatula compared to susceptible (Kamphuis et al. 2012). In our study, the number of salivation events was slightly higher among aphids feeding on S-NIL plants, but the time to the first salivation (E1) event and duration of salivation (E1) in phloem elements did not differ across the two lines. 
Phloem based resistance has been reported in multiple studies that only observed differences in ingestion (E2) phase duration, similar to our results. Phloem based resistance in $M$. truncatula to both the bluegreen aphid (Acyrthosiphon kondoi) (Klinger et al. 2005) and pea aphid (Gao et al. 2008) resulted in significantly longer periods of ingestion (E2) without an observed difference in salivation (E1) phases compared to susceptible $M$. truncatula. This difference in only ingestion time could be the result of deposition of phloem proteins or callose acting as physical blockages to sap ingestion, or indicative of the biosynthesis of resistance factors locally in response to aphid feeding (Klinger et al. 2005; Kehr 2006; Furch et al. 2007; Gao et al. 2008). Identifying the mechanism of phloem-based resistance will require further EPG experiments combined with microscopy studies to visualize occlusions that occur following specific durations of phloem contact by aphids (Medina-Ortega and Walker 2015; Peng and Walker 2020).

Aphid choice assays support EPG evidence suggesting a surface-level antixenosis resistance phenotype in addition to the phloem level antibiosis. Aphids preferred to settle and feed on S-NIL leaves over R-NIL leaves in two-way choice tests (Fig. 6). And aphids initially released on an R-NIL leaf preferred to disperse to S-NIL leaves over short time frames ( $2 \mathrm{~h}$ post-release) (Fig. 7B). This dispersion level was not observed when the R-NIL release leaf was paired with an R-NIL choice leaf (Res-Res) at the same time point, indicating the presence of additional attractive (S-NIL) or repellent (R-NIL) factors that affect the aphids' dispersal decisions. These differences in aphid preference and dispersal are consistent with the surfacelevel resistance identified by the delayed first probe on the R-NIL observed in the EPG analysis (Table 1) demonstrating the cowpea aphids' reluctance to initiate feeding on the resistant plants. This kind of antixenosis could be mediated by differences in constitutive volatile emissions from R-NIL vs. S-NIL hosts, or by surface-level characteristics such as epicuticular waxes.

\section{Conclusion}

Cowpea aphids are a serious threat to food security in areas that rely on cowpea as a staple food crop because of the unique damage condition they induce on their host plants. The best way to prevent this damage in the field is through the development of resistant cowpea lines, as pesticides are expensive and harmful to the environment (Souleymane et al. 2013). Characterization of the resistant cowpea line CB77, developed from an African cowpea and introgressed into elite California blackeye cultivar, indicates that the resistance mechanism acts mainly via antibiosis, with a secondary antixenosis effect evident from behavioral assays. The antibiosis component appears to function at the level of the phloem to block sap ingestion, ultimately, affecting both aphid growth and fecundity. The antixenosis component may be mediated by volatiles, leaf surface characteristics, or a combination of these two aspects, and acts to deter aphids from initiating settling and feeding on resistant hosts. Further investigations of the resistant and susceptible cowpea NILs (CB77 and CB46, respectively), using EPG combined with microscopy, global gene expression analysis and defense hormone profiles, may shed light on phloem-mediated resistance mechanisms acting over short time frames as well as defense signaling pathways operating over prolonged host-aphid interactions. Ultimately, this information will inform future breeding efforts to 
develop and deploy elite cultivars that provide robust cowpea resistance under a variety of crop conditions.

\section{Declarations}

\section{Funding}

This research is partly funded by the United States Department of Agriculture, National Institute of Food and Agriculture, Hatch project 1017522 to IK.

\section{Conflicts of interest/Competing interests}

The authors declare that the research was conducted in the absence of any commercial or financial relationships that could be construed as a potential conflict of interest.

\section{Availability of data and material}

The datasets generated during the current study are available from the corresponding author on reasonable request.

\section{Code availability}

Not applicable.

\section{Authors' contributions}

IK conceived the project. IK, KM and PN designed the experiments. JM and QC conducted the experiments. $\mathrm{KM}, \mathrm{JM}, \mathrm{IK}, \mathrm{QC}$ and $\mathrm{PN}$ analyzed the data. IK, $\mathrm{KM}$, and JM wrote the manuscript with input from all other authors.

\section{Ethics approval}

No approval of research ethics committees was required for this study because experimental work was conducted using an unregulated invertebrate species.

\section{Consent to participate}

Not applicable.

\section{Consent for publication}

Not applicable.

\section{Acknowledgements}

We thank Dr. Philip Roberts (UC Riverside) for the cowpea seeds and cowpea aphids. 


\section{References}

1. Alvarez AE, Tjallingii WF, Garzo E, Vleeshouwers V, Dicke M, Vosman B (2006) Location of resistance factors in the leaves of potato and wild tuber-bearing Solanum species to the aphid Myzus persicae. Entomol Exp Appl 121:145-157. https://doi.org/10.1111/j.1570-8703.2006.00464.x

2. Blackman RL, Eastop VF (1994) Aphids on the world's trees: An identification and information guide. CAB International, Wallingford

3. Burd J, Burton RL (1992) Characterization of plant damage caused by Russian wheat aphid (Homoptera: Aphididae). J Econ Entomol 85:2017-2022. https://doi.org/10.1093/jee/85.5.2017

4. Burd J, Burton RL, Webster JA (1993) Evaluation of Russian wheat aphid (Homoptera: Aphididae) damage on resistant and susceptible hosts with comparisons of damage ratings to quantitative plant measurements. J Econ Entomol 86:974-980. https://doi.org/10.1093/jee/86.3.974

5. Cervantes FA, Backus EA (2018) EPG waveform library for Graphocephala atropunctata (Hemiptera: Cicadellidae): effect of adhesive, input resistor, and voltage levels on waveform appearance and stylet probing behaviors. J Insect Physiol 109:21-40.

https://doi.org/10.1016/j.jinsphys.2018.05.008

6. Chan CK, Forbes AR, Raworth DA (1991) Aphid-transmitted viruses and their vectors of the world. Research Branch, Agriculture Canada, Ottawa

7. Deol GS, Reese JC, Gill BS, Wilde GE, Campbell LR (2001) Comparative chlorophyll losses in susceptible wheat leaves fed upon by Russian wheat aphids or greenbugs (Homoptera: Aphididae). $J$ Kans Entomol Soc 74:192-198

8. Diaz-Montano J, Reese JC, Louis J, Campbell LR, Schapaugh WT (2007) Feeding behavior by the soybean aphid (Hemiptera: Aphididae) on resistant and susceptible soybean genotypes. J Econ Entomol 100:984-989. doi:10.1603/0022-0493(2007)100[984:fbbtsa]2.0.co;2

9. Ebert TA, Backus EA, Cid M, Fereres A, Rogers ME (2015) A new SAS program for behavioral analysis of electrical penetration graph data. Comput Electron Agric 116:80-87.

https://doi.org/10.1016/j.compag.2015.06.011

10. Elawad HOA, Hall AE (1987) Influences of early and late nitrogen fertilization on yield and nitrogen fixation of cowpea under well-watered and dry field conditions. Field Crops Res 12:197-222. https://doi.org/10.1016/0378-4290(87)90012-8

11. Fery RL (1990) The cowpea: production, utilization, and research in the United States. Hort Rev 12::197-222. doi:10.1002/9781118060858.ch4

12. Furch ACU, Hafke JB, Schulz A, van Bel AJE (2007) Ca2+-mediated remote control of reversible sieve tube occlusion in Vicia faba. J Exp Bot 58:2827-2830. doi:10.1093/jxb/erm143

13. Gabrys B, Tjallingii WF, Van Beek TA (1997) Analysis of EPG recorded probing by cabbage aphid on host plant parts with different glucosinolate contents. J Chem Ecol 23:1661-1667. https://doi.org/10.1023/B:JOEC.0000006442.56544.1a 
14. Gao L, Klinger J, Anderson JP, Edwards OR, Singh KB (2008) Characterization of pea aphid resistance in Medicago truncatula. Plant Physiol 146:996-1009. doi:10.1104/pp.107.111971

15. Giordanengo P (2014) EPG-Calc: a PHP-based script to calculate electrical penetration graph (EPG) parameters. Arthropod-Plant Inte 8:163-169. https://doi.org/10.1007/s11829-014-9298-z

16. Goggin FL, Quisenberry S, Ni X (2017) Feeding injury. In: van Emden HF, Harrington R (eds) Aphids as Crop Pests, 2nd ed. CAB International, pp 303-322

17. Hall AE (2004) Breeding for adaptation to drought and heat in cowpea. Eur J Agron 21:447-454. https://doi.org/10.1016/j.eja.2004.07.005

18. Hall AE, Ismail AM, Ehlers JD, Marfo KO, Cisse N, Thiaw S et al (2002) Breeding cowpeas for tolerance to temperature extremes and adaptation to drought. In: Fatokun CA, Tarawali SA, Singh BB, Kormawa PM, Tamo M (eds) Challenges and Opportunities for Enhancing Sustainable Cowpea Production. Intl Inst Tropical Agric, Ibadan, pp 14-21

19. Hill CB, Li Y, Hartman GL (2004) Resistance to the soybean aphid in soybean germplasm. Crop Sci 44:98-106. https://doi.org/10.2135/cropsci2004.9800

20. Hill CB, Li Y, Hartman GL (2006a) A single dominant gene for resistance to the soybean aphid in the soybean cultivar Dowling. Crop Sci 46:1601-1605. https://doi.org/10.2135/cropsci2005.11-0421

21. Hill CB, Li Y, Hartman GL (2006b) Soybean aphid resistance in soybean Jackson is controlled by a single dominant gene. Crop Sci 46:1606-1608. https://doi.org/10.2135/cropsci2005.11-0438

22. Huynh BL, Ehlers JD, Ndeve A, Wanamaker S, Lucas MR, Close TJ et al (2015) Genetic mapping and legume synteny of aphid resistance in African cowpea (Vigna unguiculata L. Walp.) grown in California. Mol Breed 35:36. doi:10.1007/s11032-015-0254-0

23. Jackai L, Daoust R (1986) Insect pests of cowpeas. Annu Rev Entomol 31:95-119. doi:10.1146/annurev.en.31.010186.000523

24. Kaloshian I, Walling LL (2016) Hemipteran and dipteran pests: Effectors and plant host immune regulators. J Integr Plant Biol 58:350-361. doi:10.1111/jipb.12438

25. Kamphuis LG, Gao L, Singh KB (2012) Identification and characterization of resistance to cowpea aphid (Aphis craccivora Koch) in Medicago truncatula. BMC Plant Biol 12::101. doi:10.1186/14712229-12-101

26. Kehr J (2006) Phloem sap proteins: their identities and potential roles in the interaction between plants and phloem-feeding insects. J Exp Bot 57:767-774. https://doi.org/10.1093/jxb/erj087

27. Klinger J, Creasy R, Gao L, Nair RM, Jacob HS, Edwards OR et al (2005) Aphid resistance in Medicago trunculata involves antixenosis and phloem-specific, inducible antibiosis, and maps to a single locus flanked by NBS-LRR resistance gene analogs. Plant Physiol 137:1445-1455. doi:10.1104/pp.104.051243

28. Langyintuo AS, Lowenberg-DeBoer J, Faye M, Lamber D, Ibro G, Moussa B et al (2003) Cowpea supply and demand in west and central Africa. Field Crops Res 82:215-231. https://doi.org/10.1016/S0378-4290(03)00039-X 
29. Martin B, Collar JL, Tjallingii WF, Fereres A (1997) Intracellular ingestion and salivation by aphids may cause the acquisition and inoculation of non-persistently transmitted plant viruses. Gen Virol 78:2701-2705. doi:10.1099/0022-1317-78-10-2701

30. Mauck KE, De Moraes CM, Mescher MC (2010) Deceptive chemical signals induced by a plant virus attract insect vectors to inferior hosts. Proc Natl Acad Sci USA 107:3600-3605. doi:10.1073/pnas.0907191107

31. Medina-Ortega KJ, Walker GP (2015) Faba bean forisomes can function in defence against generalist aphids. Plant Cell Environ 38:1167-1177. https://doi.org/10.1111/pce.12470

32. Miles PW (1990) Aphid salivary secretions and their involvement in plant toxicoses. In: Campbell RK, Eikenbary RD (eds) Aphid-Plant Genotype Interactions. Elsevier, Amsterdam, pp 131-147

33. Miles PW (1999) Aphid saliva. Biol Rev 74:41-85. doi:10.1017/S0006323198005271

34. Nicholson SJ, Hartson SD, Puterka GJ (2012) Proteomic analysis of secreted saliva from Russian wheat aphid (Diuraphis noxia Kurd.) biotypes that differ in virulence to wheat. J Proteomics 75:2252-2268. doi:10.1016/j.jprot.2012.01.031

35. Nicholson SJ, Puterka GJ (2014) Variation in the salivary proteomes of differentially virulent greenbug (Schizaphis graminum Rondani) biotypes. J Proteomics 105:186-203. doi:10.1016/j.jprot.2013.12.005

36. Obopile M (2006) Economic threshold and injury levels for control of cowpea aphid, Aphis crassivora Linnaeus (Homoptera: Aphididae), on cowpea. Afr Plant Prot 12:111-115

37. Omoigui LO, Ekeuro GC, Kamara AY, Bello LL, Timko MP, Ogunwolu GO (2017) New sources of aphids [Aphis craccivora (Koch)] resistance in cowpea germplasm using phenotypic and molecular marker approaches. Euphytica 213:178. https://doi.org/10.1007/s10681-017-1962-9

38. Peng H, Walker GP (2020) Sieve element occlusion provides resistance against Aphis gossypii in TGR-1551 melons. Insect Sci 27:33-48. doi:10.1111/1744-7917.12610

39. Reynolds DR (1999) Capnodium citri: The sooty mold fungi comprising the taxon concept. Mycopathologia 148:141-147. https://doi.org/10.1023/A:1007170504903

40. Schwarzkopf A, Rosenberger D, Niebergall M, Gershenzon J, Kunert G (2013) To feed or not to feed: plant factors located in the epidermis, mesophyll, and sieve elements influence pea aphid's ability to feed on legume species. PloS One 8(9):e75298. https://doi.org/10.1371/journal.pone.0075298

41. Singh BB (2014) Cowpea: The food legume of the 21st Century. Crop Science Society of America, Madison

42. Singh BB, Ehlers JD, Sharma B, Freire FR (2002) Recent progress in cowpea breeding. In: Fatokun CA, Tarawali BB, Singh BB, Kormawa PM, Tamo M (eds) Proceedings of the World Cowpea Conference III, pp 22-40

43. Singh SR, Allen DJ (1980) Pests, diseases, resistance and protection in cowpea. In: Summerfield RJ, Bunting AH (eds) Advances in legume science. Royal Botanic Gardens, Richmond, pp 419-443 
44. Smith CM (1989) Plant resistance to insects: A Fundamental Approach. John Wiley \& Sons, New York

45. Song N, Zhang H, Lu H, Cai W (2016) All 37 mitochondrial genes of aphid Aphis craccivora obtained from transcriptome sequencing: implications for the evolution of aphids. PloS One 11:e0157857. https://doi.org/10.1371/journal.pone.0157857

46. Souleymane A, Aken'Ova ME, Fatokun CA, Alabi OY (2013) Screening for resistance to cowpea aphid (Aphis craccivora Koch) in wild and cultivated cowpea (Vigna unguiculata L. Walp.) accessions. Int J Environ Sci Technol 2:611-621. doi:10.13140/2.1.4717.9207

47. Spiller NJ, Koenders L, Tjallingii WF (1990) Xylem ingestion by aphids - a strategy for maintaining water balance. Entomol Exp Appl 55(2). https://doi.org/10.1111/j.1570-7458.1990.tb01352.x

48. Studham ME, Maclntosh GC (2013) Multiple phytohormone signals control the transcriptional response to soybean aphid infestation in susceptible and resistant soybean plants. Mol Plant Microbe Interact 26:116-129. doi:10.1094/MPMI-05-12-0124-FI

49. Sun M, Voorrips RE, Steenhuis-Broers G, Van't Westende W, Vosman B (2018) Reduced phloem uptake of Myzus persicae on an aphid resistant pepper accession. BMC Plant Biol 18:138. doi:10.1186/s12870-018-1340-3

50. Timko MP, Singh BB (2008) Cowpea, a multifunctional legume. In: Moore PH, Ming R (eds) Genomics of Tropical Crop Plants Springer, New York, pp 227-258

51. Tjallingii WF (1987) Stylet penetration activities by aphids. New correlations with electrical penetration graphs. In: Laberyrie V, Fabres G, Lachaise D (eds) Insect-Plants. Junk, Dordrecht, pp 301-306

52. Tjallingii WF (1988) Electrical recording of stylet penetration activities. In: Minks AK, Harrewijn P(eds) Aphids, their biology, natural enemies and control. Elsevier Science Publishers, Amsterdam, pp 95108

53. Tjallingii WF (1990) Continuous recording of stylet penetration activities by aphids. In: Campbell RK, Eikenbary RD (eds) Aphid-plant Genotype Interactions. Elsevier, Amsterdam, pp 89-99

54. Tjallingii WF (2006) Salivary secretions by aphids interacting with proteins of phloem wound responses. J Exp Bot 57:739-745. doi:10.1093/jxb/erj088

55. Tjallingii WF, Esch TH (1993) Fine-structure of aphid stylet routes in plant-tissues in correlation with EPG signals. Physiol Entomol 18:317-328. doi:10.1111/j.1365-3032.1993.tb00604.x

56. Van Helden $M$, Tjallingii WF (1993) Tissue localization of lettuce resistance to the aphid $N$. ribisnigri using electrical penetration graphs. Entomol Exp Appl 68:269-278. https://doi.org/10.1111/j.15707458.1993.tb01713.x

57. Walker GP, Medina-Ortega KJ (2012) Penetration of faba bean sieve elements by pea aphid does not trigger forisome dispersal. Entomol Exp Appl 144:326-335. https://doi.org/10.1111/j.15707458.2012.01297.x

\section{Figures}




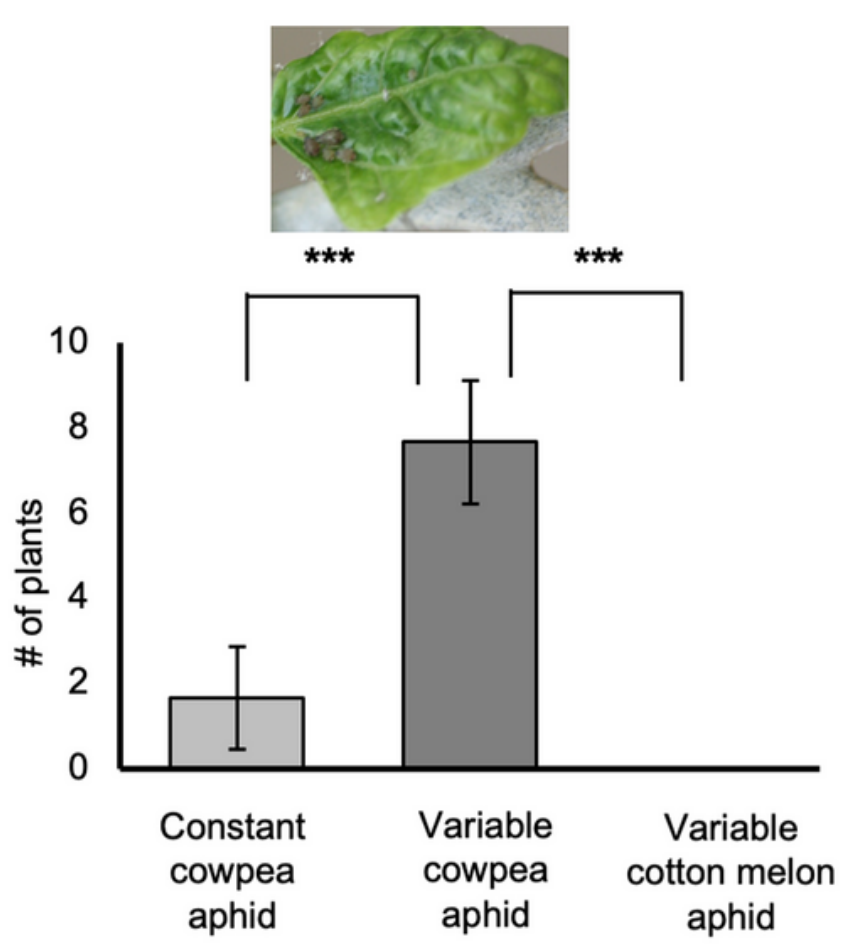

C
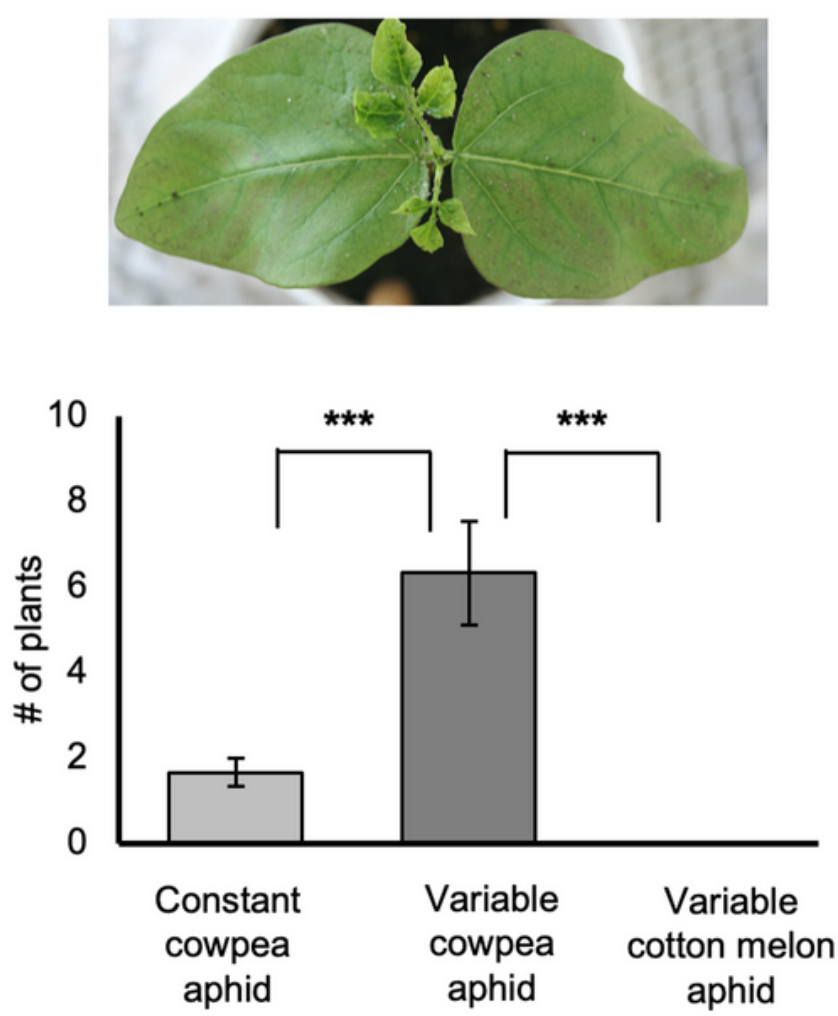

b
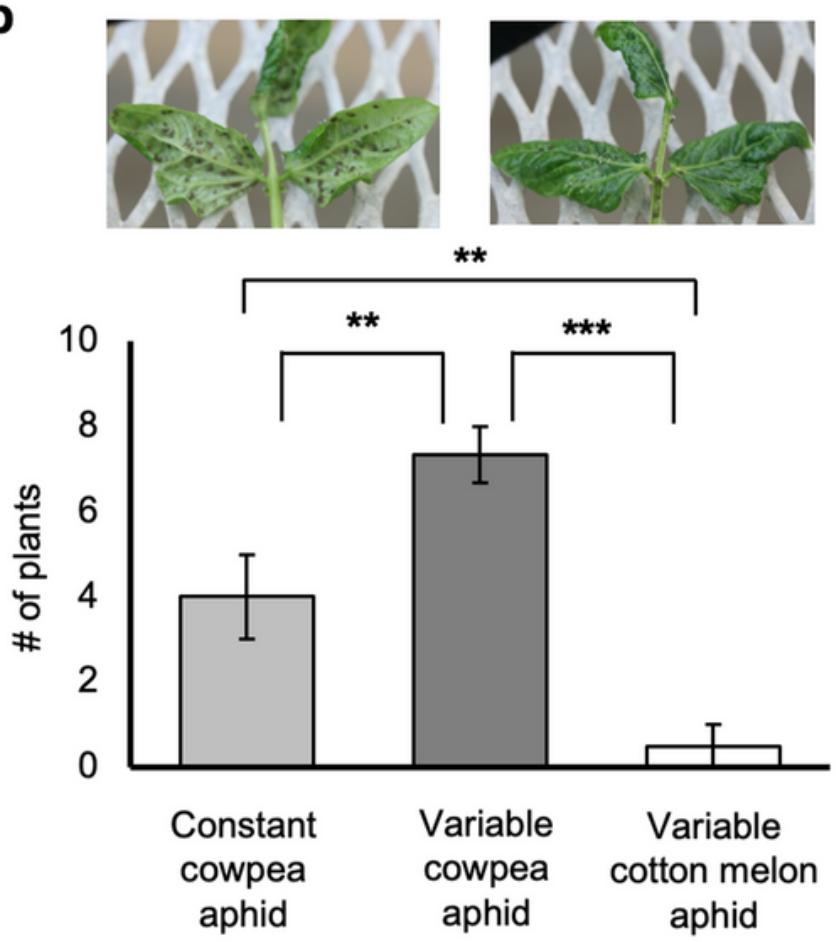

d
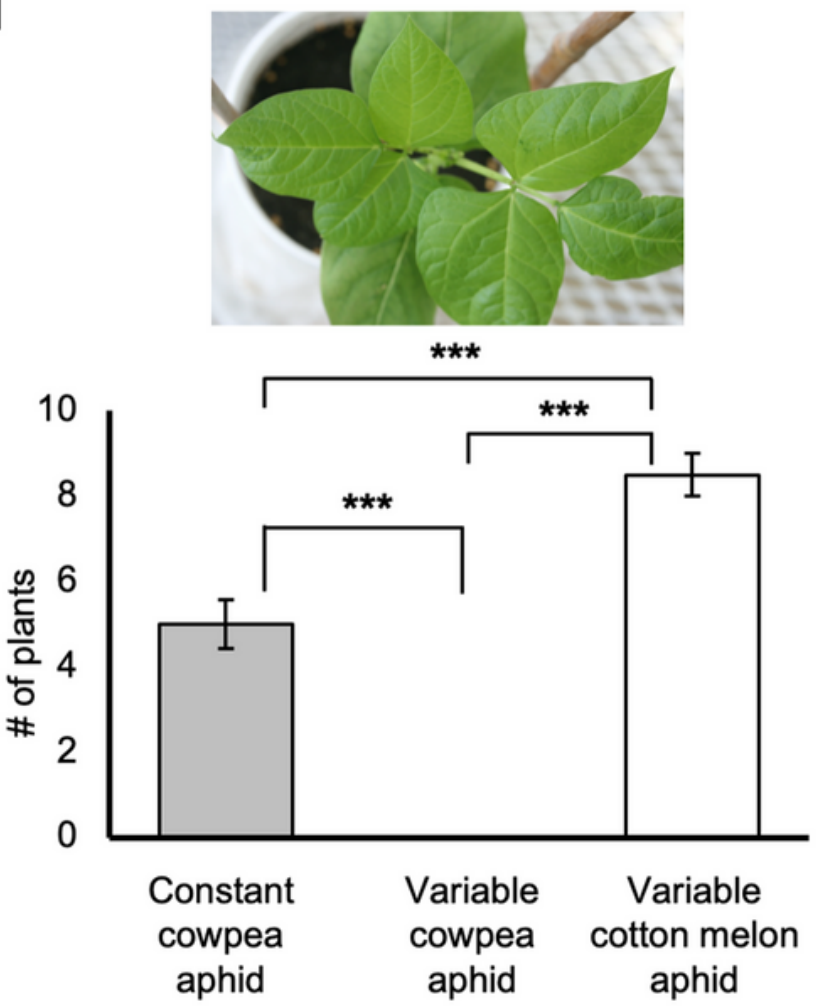

\section{Figure 1}

The number of cowpea plants showing damage symptoms by cowpea aphids or cotton melon aphids. The symptoms observed were a) chlorosis, b) pseudogalling, c) stunted growth, and d) no damage. A picture representing each symptom (or lack of it) is displayed above each graph. All photos were taken on the same day with plants infested at the same time. The constant cowpea aphid density was maintained at 15 aphids for the entirety of an experiment. Aphids in the variable aphid density were allowed to grow 
without any restriction. The experiment was performed three times with 10 plants per aphid density except for one replicate where cotton melon aphid had only 8 plants. Constant cowpea aphid $n=30$, variable cowpea aphid $n=30$, variable cotton melon aphid $n=28$. Values are expressed as the mean and SE. Analyses were performed with one-way ANOVA followed by Tukey's HSD test. Asterisks indicate significant differences ** $p<0.01$, and $* * * p<0.001$

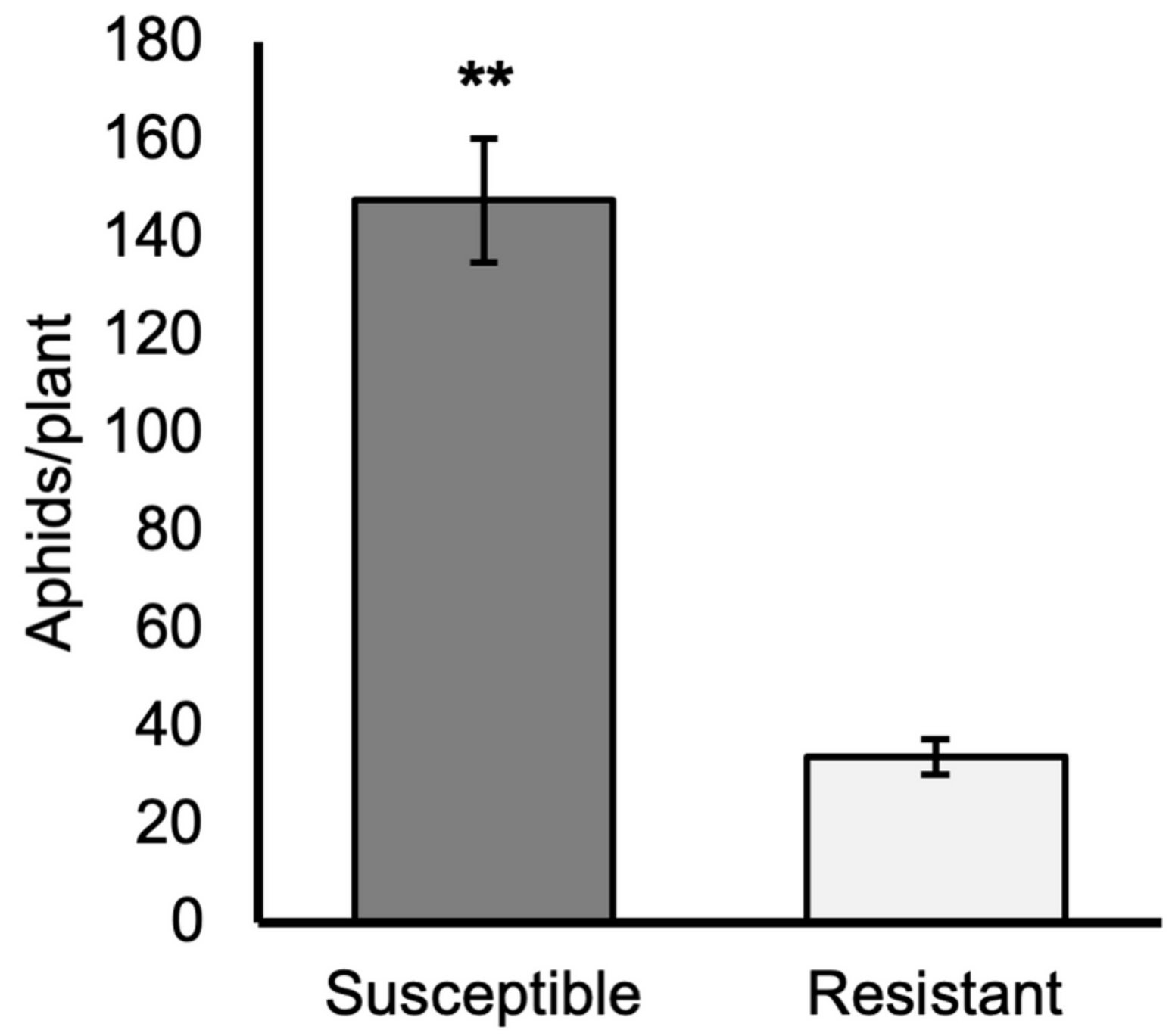

Figure 2

Cowpea aphid population growth on susceptible and resistant cowpea NILs. Plants were infested with 20 adult aphids for 6 days. The difference in aphid population between the two plant NILs $(n=15)$ was analyzed using two-tailed t-test. Asterisks indicate significance ** $p<0.01$ 
a

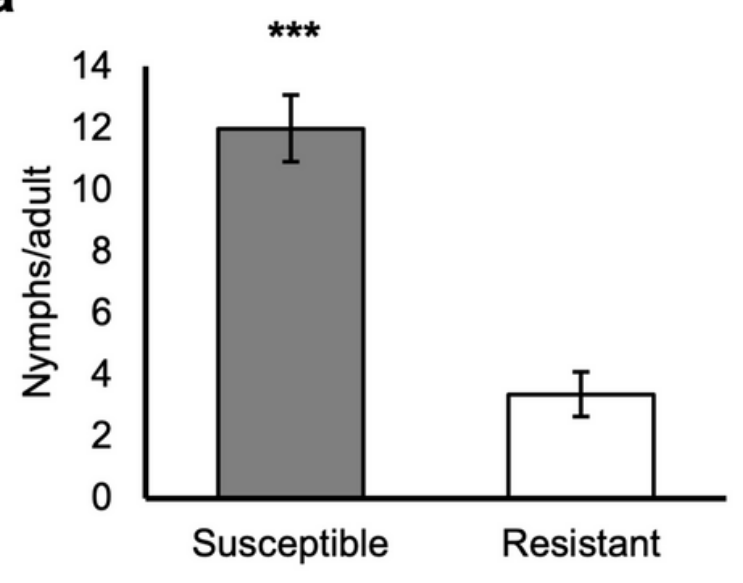

b

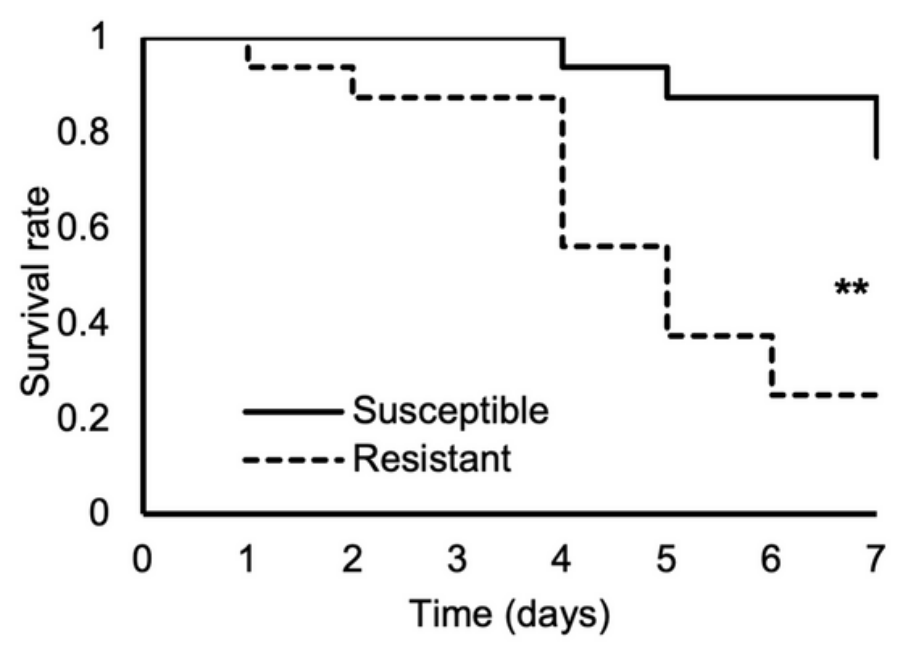

\section{Figure 3}

Adult cowpea aphid performance on susceptible and resistant cowpea. a) Fecundity of age synchronized one-day-old adult aphids on resistant or susceptible plants. Values are the means and SE of $n=16 . b$ ) Survival rate of one-day-old adults on susceptible or resistant cowpea. Aphid performances were monitored for 7 days, $n=16$. The asterisks indicate a significant difference between aphids on susceptible and resistant cowpea plants (GLM, Chi-sq $=41.704 ; * \star \star ~ p<0.001$ for the daily fecundity and Cox model, Chi-sq $=8.049 ; * \star p=0.005$ for the aphid survival rate)

a

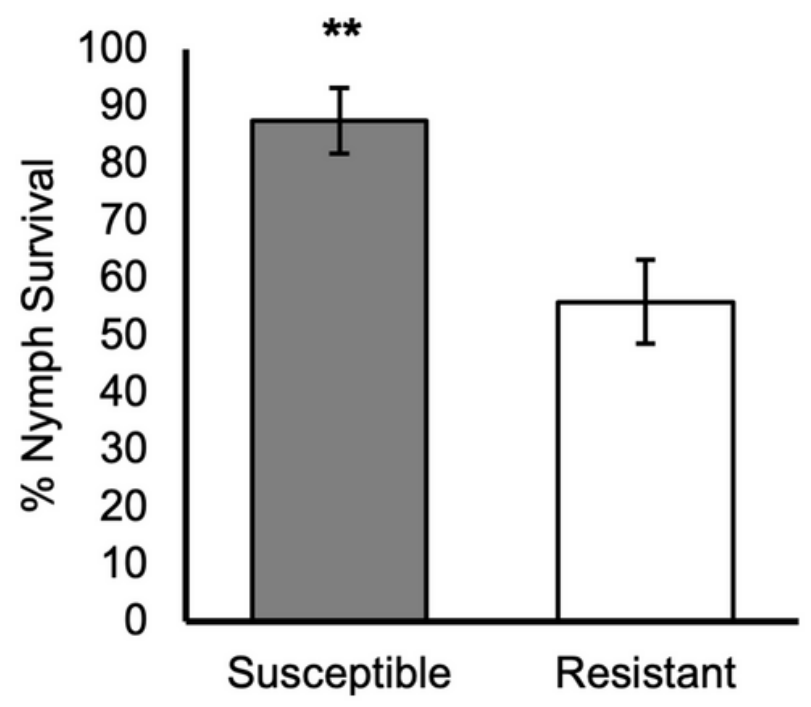

b

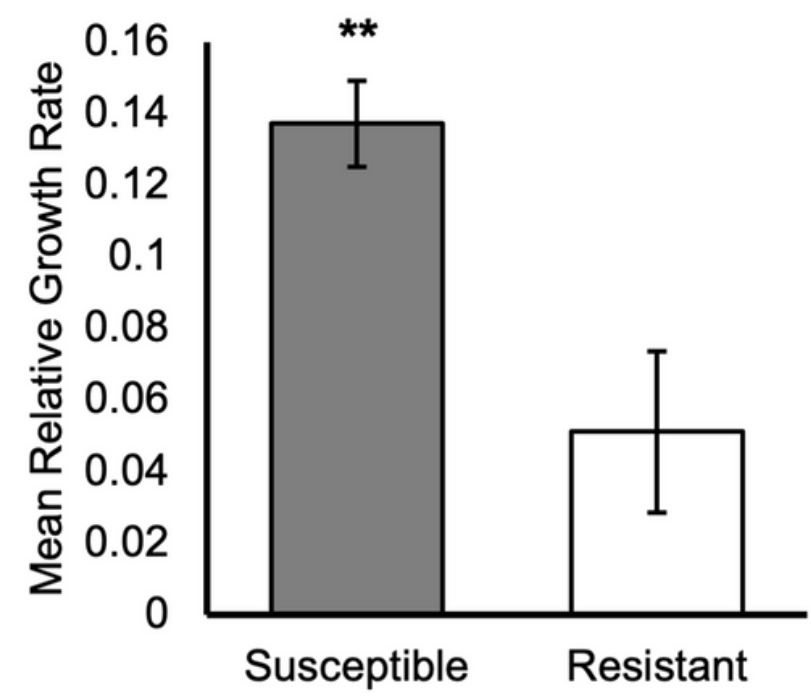

\section{Figure 4}

Cowpea aphid nymphal growth rate and survival on susceptible and resistant cowpea. Ten newborn nymphs were clip-caged onto a single leaf of susceptible or resistant plants for 6 days. Values are the means and SE of $n=12$. a) Nymphal survival b) Mean relative growth rate (MRGR) (MRGR = (Log(Avgsurviving nymphs) - Log(Avgday-old nymphs))/Days on Plant)/Days on Plant). Average weight 
of 20 day-old nymphs were used as base value. Analysis was performed by two-tailed t-test. Asterisks indicate significance ** $p<0.01$

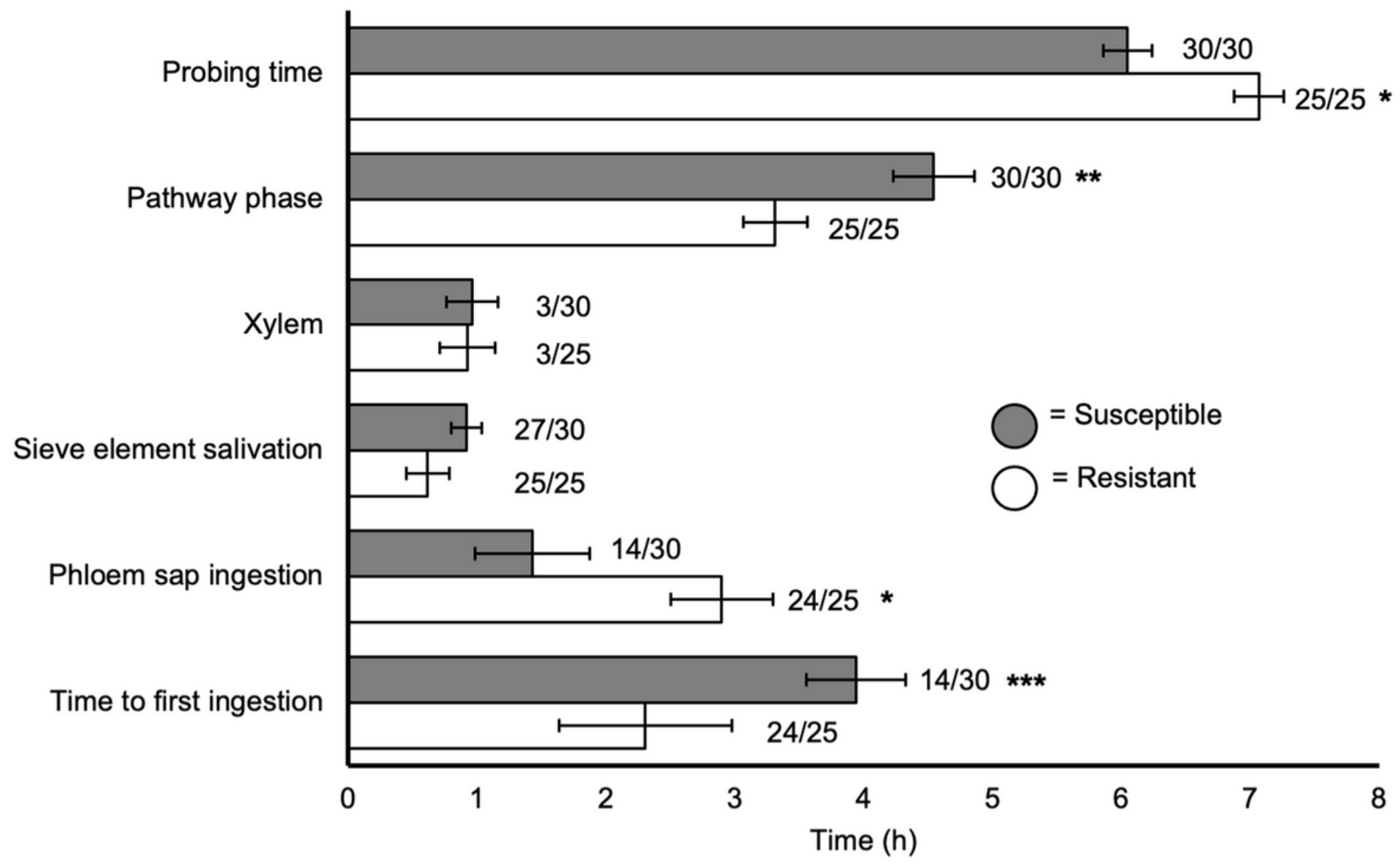

\section{Figure 5}

Electrical penetration graphs (EPGs) of cowpea aphids feeding on susceptible and resistant cowpea. Probing time indicates the time the aphid stylets were in the plant. The pathway phase indicates the time the aphid stylets are in the mesophyll or parenchyma cells (C phase + potential drops). The xylem phase indicates the time the aphid stylets are in the xylem (G phase). The sieve element salivation is the time the aphid is salivating into the sieve element (E1 phase). The phloem sap ingestion is the time the aphid is ingesting the plant phloem sap (E2 phase). The time to first ingestion is the average time it took for the aphid to first ingest phloem sap. Data is based on 25 and 30 aphids tested on susceptible and resistant cowpea NILs, respectively. The asterisks indicate a significant difference between the plants (GLM models, * $p<0.05, * * p<0.01, * \star * p<0.001$ ) 


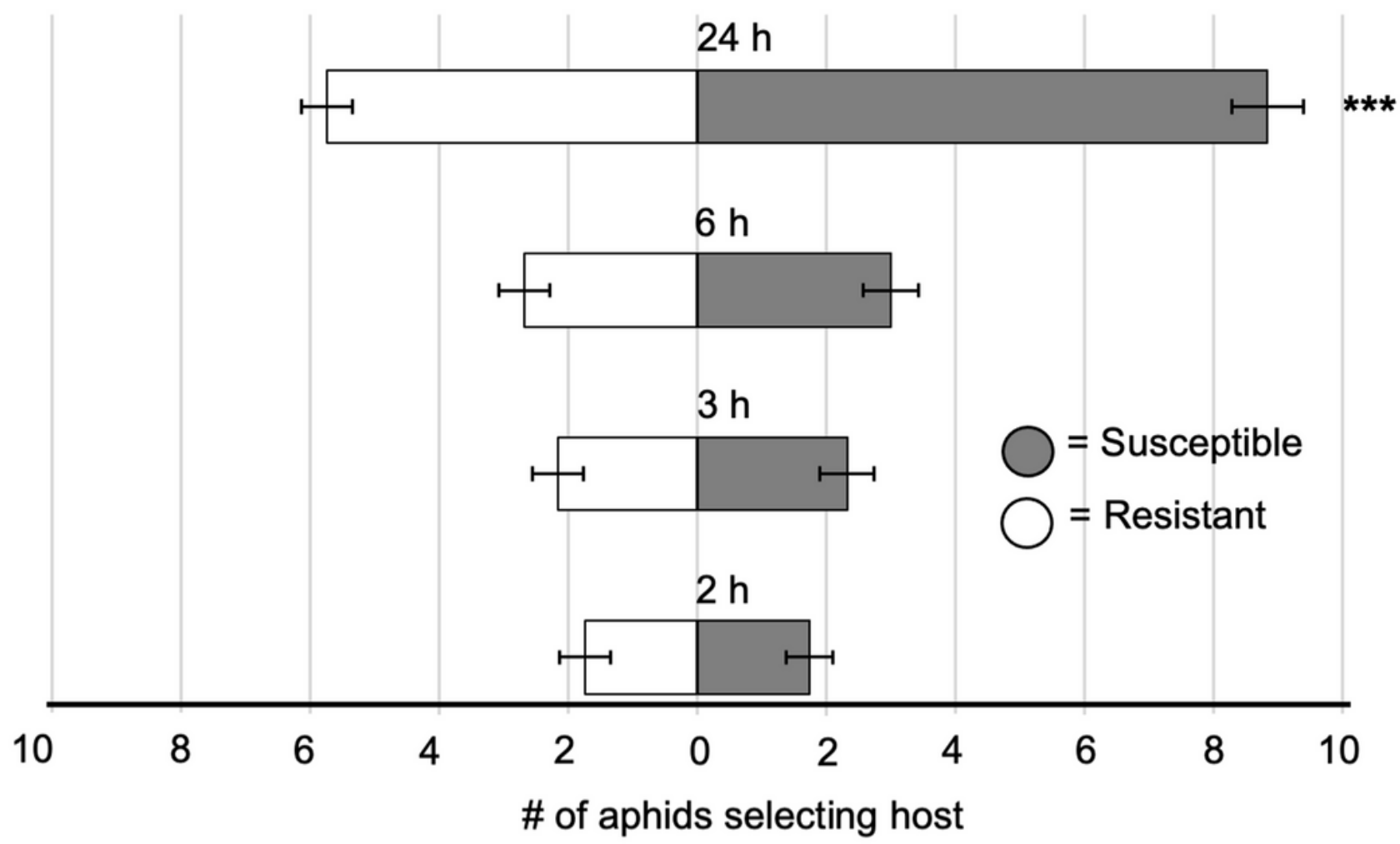

Figure 6

Aphid choice assay. Twenty cowpea aphids were introduced into a large petri dish arena to choose between a unifoliate leaf from susceptible or resistant cowpea NILs on either side. Values are the mean and SE of $n=19$. The number of adult aphids on either leaf line was documented at the indicated time points. Analysis with both Friedman (full model) and Kruskal-Wallis (individual time points) tests were performed. Asterisks indicate significance * $p<0.05, * * p<0.01$, $* * * p<0.001$ 

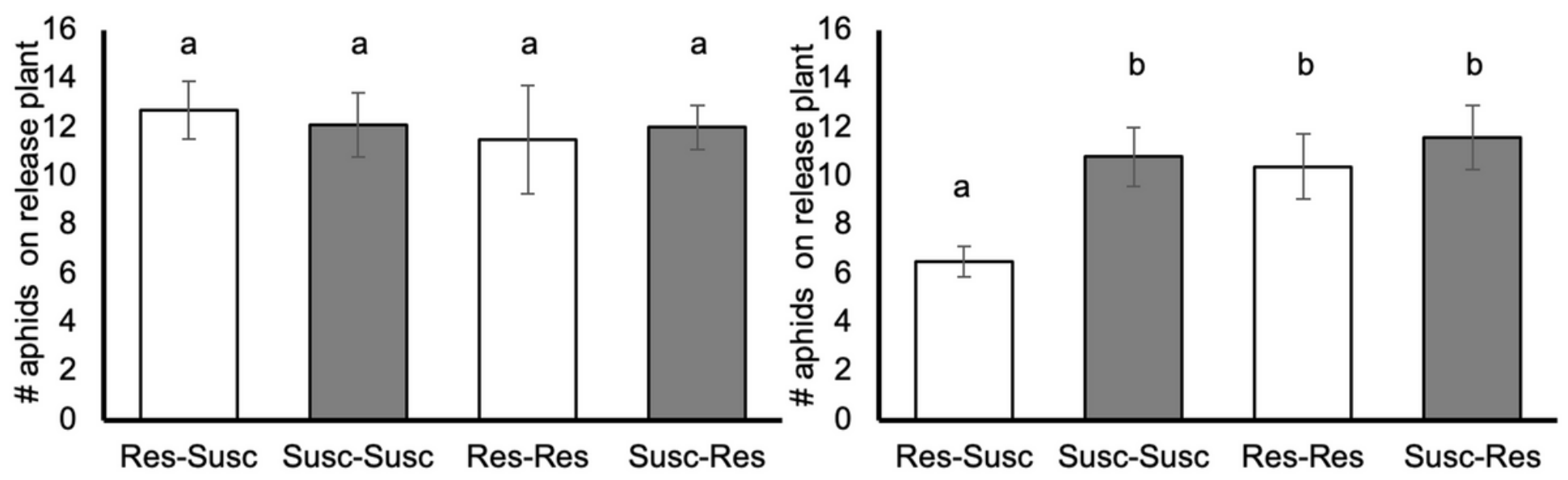

C

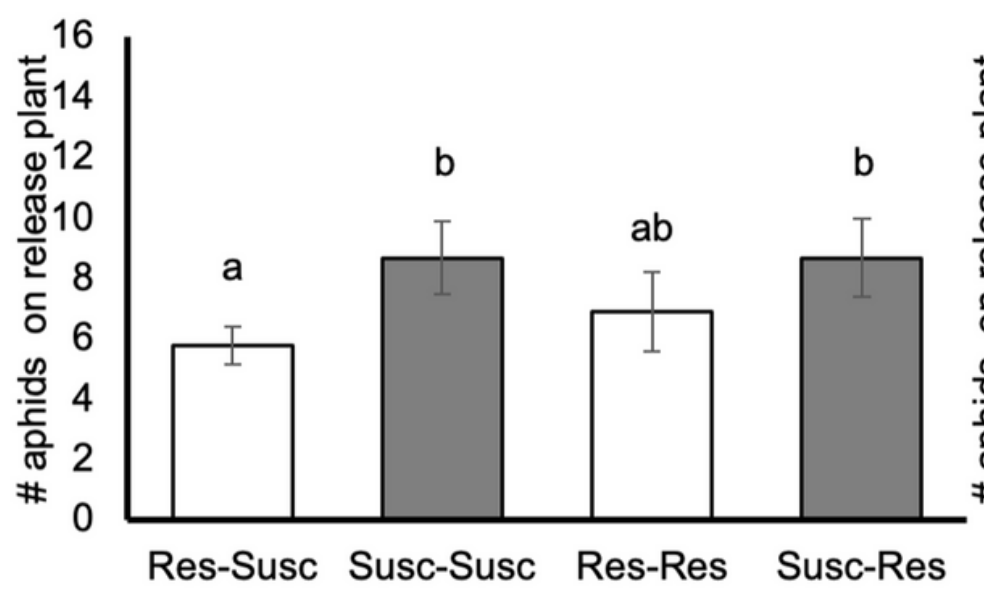

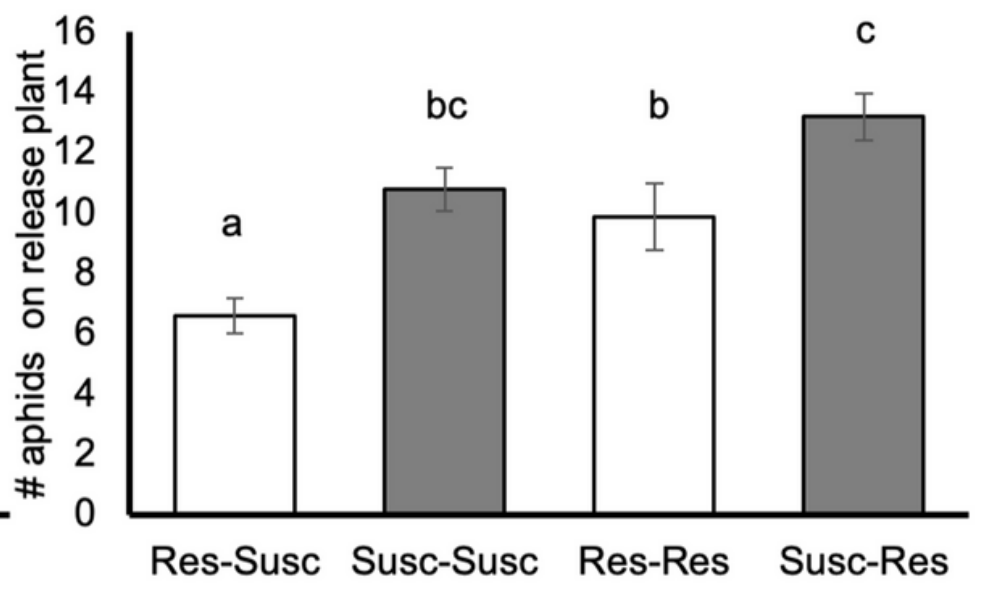

Figure 7

Cowpea aphids remaining on susceptible or resistant cowpea after initial release. Twenty cowpea aphids were introduced through filter paper to a resistant cowpea unifoliate leaf in a petri dish arena. Either a susceptible or resistant cowpea leaf was placed opposite in the arena. The location of the aphids was monitored at a) $1 \mathrm{~h}$, b) $2 \mathrm{~h}, \mathrm{c}) 6 \mathrm{~h}$, and d) $24 \mathrm{~h}$. Values are the mean and SE of $n=10$. Dispersal level was compared to the appropriate baseline dispersal through generalized linear models (GLM) followed by Tukey's HSD test. Asterisks indicate significant differences ** $p<0.01$, and *** $p<0.001$ 